\title{
UMA EXPERIÊNCIA COM GRUPOS DE PROMOÇÃO DA SAÚDE MATERNO-INFANTIL NO SISTEMA PRISIONAL
}

\section{Gabriel Savaris Ignácio'}

Resumo: Os presídios brasileiros representam uma complexa questão de saúde pública na qual as mulheres caracterizam-se como uma população bastante vulnerável devido às especificidades de saúde, gênero e maternidade. Através de um relato de experiência, analisou-se grupos de promoção da saúde em uma Unidade Materno Infantil de uma penitenciária feminina do Rio Grande do Sul. Os resultados possibilitaram uma compreensão sobre os obstáculos no acesso às políticas públicas, do exercício da maternidade e da vida nesse contexto. Além disso, indicaram dispositivos terapêuticos para promoção da saúde e de articulação de saberes entre usuárias e trabalhadores/as do Sistema Único de Saúde.

Palavras-chave: Promoção da saúde; maternidade; sistema prisional.

Abstract: The brazilians prisons represents a complex public health care issue in which women are characterized as most vulnerable owing to their specificities of health, gender and motherhood. Through an experience report, there were analyzed health promotion groups in a Maternal and Child Unit of a female penitentiary in Rio Grande do Sul. The results allowed an understanding of the obstacles in the access to public health policies, the exercise of maternity and life in this context. Whatsmore, these also indicated therapeutic tools to promote health and articulation of knowledge between Unified Health System users and workers.

Keywords: Health promotion; motherhood; prison system.

\section{Introdução}

A questão da População Privada de Liberdade (PPL) no Sistema Prisional tem chamado a atenção de diferentes entidades no Brasil e no mundo, principalmente no que se refere à garantia dos Direitos Humanos e do acesso às Políticas Públicas de Saúde e de Assistência Social (WHO, 2003). Os levantamentos de dados mais recentes apontam que o perfil da população prisional é composto majoritariamente por jovens, negros, de baixa renda e escolaridade, estando assim, em situações de vulnerabilidade social e econômica, bem como suscetiveis a condições adversas de saúde (BRASIL, 2014a; 2014b; 2015).

O exponencial aumento da PPL nos últimos anos tem seguido as marcas desse

1 Pontifícia Universidade Católica do Rio Grande do Sul. E-mail: gbsignacio@gmail.com. 
perfil e aponta, ainda, para um crescente número de mulheres encarceradas: entre os anos de 2000 a 2014, esse grupo ampliou-se em 567,4\% no Brasil (ao passo que o aumento da PPL masculina foi de 220,20\%, no mesmo período). No caso do Estado do Rio Grande do Sul (RS), entre os anos de 2007 a 2014, este aumento foi de 41\% (BRASIL, 2014b). Assim, considerado o quarto país com maior população feminina privada de liberdade do mundo, em junho de 2014, o Brasil contava com 37.380 mulheres presas e 542.401 homens presos, totalizando 579.781 pessoas privadas de liberdade (BRASIL, 2014a; BRASIL, 2015).

A partir de uma caracterização da PPL, é possivel perceber que essa possui cor e classe. Isso se justifica a partir do reconhecimento de que as ações repressivas à criminalidade têm se dado justamente nas periferias dos grandes centros urbanos. Tais ações, advindas das políticas proibicionistas de "guerra às drogas", são adotadas pelo Estado brasileiro (através do sistema penal de justiça e de segurança pública) aos moldes dos Estados Unidos da América e se dão nas marcas da criminalização da pobreza. Isso vem a resultar não só em um encarceramento em massa, mas, também, em altos índices de homicídios da juventude negra periférica (WACQUANT, 2001; ZAFFARONI, 2013; BRASIL, 2015).

Assim, a análise dessa questão expõe o caráter de classe do Estado burguês na captura dos sujeitos inseridos de forma precária na produção social de riqueza, uma vez que essa se dá sobre os estratos mais desfavorecidos e marginalizados da classe trabalhadora e do lumpemproletariado ${ }^{2}$, ou seja, pretos, pobres e marginais (WACQUANT, 2001; SOARES \& GUINDANI, 2007). Ainda segundo Wacquant (2001), sobretudo nos paises da América Latina, onde há uma profunda desigualdade social e econômica, histórica ausência democrática, subordinação ao capital internacional, industrialização recente, bem como a herança colonial e ditatorial, esse cenário é ainda mais precário. A realidade desses países tem representado um avanço no processo de pauperização das massas, além do crescimento da violência urbana. De acordo com Lessa e Tonet (2011), a essência dessa questão, em última instância, pode ser identificada na violência inerente ao modo de produção da vida na sociedade capitalista, em que uma classe detém o domínio econômico, político e ideológico sobre a outra, por intermédio do Estado.

Tendo em vista a situação de vulnerabilidade que as pessoas privadas de liberdade se encontram (mesmo antes e depois do cárcere), bem como o crescente número de mulheres presas no RS a questão da saúde da PPL vem se apresentando como ainda mais complexa. Além das mulheres estarem expostas às precárias condições sanitárias dos presídios, que caracterizam altas taxas de mortalidade e agravos infecto-contagiosos (tais como HIVIAIDS, tuberculose, sifilis, hepatites virais e outras Infecções Sexualmente Transmissiveis), essas apresentam diversos problemas relacionados à saúde mental e ao uso abusivo

\footnotetext{
2 Para Marx \& Engels (2002), o lumpemproletariado trata-se da parcela do proletariado urbano que não está
} inserida em nenhum trabalho formal (como, por exemplo, pessoas em situação de rua ou de tráfico). 
de drogas (BRASIL, 2014b).

Conjuntamente $a$ isso, a partir de uma perspectiva de gênero, nota-se que o histórico de vitimização das mulheres, seja anterior ou durante a permanência no cárcere (DOTTA; STOCK \& FUZINATTO, 2017), articula-se com um tratamento penal voltado ao gênero masculino. Essa questão representa uma extrema violência às mulheres privadas de liberdade dado a invisibilização de suas demandas específicas e, consequentemente, a negligência de aspectos como maternidade, gestação, diversidade sexual e de gênero, criminalidade, etc. (CAFFARENA et al., 2012; BRASIL, 2014a). Nesse sentido a maternidade tem chamado atenção por apresentar-se como uma condição bastante melindrosa, uma vez que seu (não) exercício em instituições prisionais, junto ao adoecimento materno, a fragilização dos vínculos materno-infantis e de um ambiente social inadequado, influenciam profundamente no desenvolvimento integral da criança, de sua saúde, da saúde da mãe e de sua família como um todo (SCHNEIDER e RAMIRES, 2007).

Assim, não há dúvidas sobre a vulnerabilidade que o aprisionamento tem representado às mulheres presas, aos seus filhos, à PPL e à sociedade. Por tanto, torna-se essencial demarcar a urgência que cabe à saúde pública em lançar olhares e desenvolver ações que vão de encontro às reais demandas dessa população, tendo em vista a superação desse quadro. É importante ressaltar que, nesta análise, parte-se de uma concepção que compreende a saúde enquanto dever do Estado e direito da população brasileira à dignidade e a preservação da vida, bem como enquanto um conjunto de fatores como alimentação, moradia, saneamento básico, acesso a serviços essenciais de saúde, educação, assistência, trabalho e lazer além de aspectos sociais, econômicos, psicológicos, comportamentais e culturais (BRASIL, 1986). É a partir da necessidade em aprofundar o entendimento sobre as questões que a maternidade levanta nos serviços de saúde à população prisional que esse relato pretende se colocar enquanto uma perspectiva crítica ao atual cenário, na intenção de colaborar com a discussão em torno desse tema desde uma experiência prática.

\section{Método}

A fim de relatar a experiência com grupos de promoção da saúde na Unidade Materno Infantil (UMI) de uma penitenciária feminina do RS, utilizou-se a "Sistematização de Experiências" (HOLLIDAY, 2006). As análises fizeram-se possiveis através da reconstrução sistemática das experiências concretas a partir de um diário de campo enquanto ferramenta de registro. Buscou-se, ainda, na perspectiva da Saúde Coletiva sobre a Promoção da Saúde (BUSS, 2000; CZERENIA e FREITAS, 2009) e nas teorias da dinâmica de grupo (PICHÓNRIVIÉRE, 1998) bases para a intervenção e análise dos processos grupais relatados. 
Partiu-se da observação de 6 desses grupos que ocorreram ao longo de um ano com média de duas horas de duração cada e com frequência irregular (em função dos diversos entraves da instituição prisional). Os grupos eram compostos por cerca de 8 mulheres (gestantes e puérperas), de faixa etária entre 18 e 30 anos. Objetivou-se compreender a experiência social, os mecanismos e as dificuldades do (não) exercício da maternidade encarcerada, os entraves no acesso à saúde dessa população e, ainda, analisar as contribuições dos dispositivos grupais na promoção da saúde. Tal experiência diz respeito a uma das ações da Linha de Cuidado Intersetorial Materno Infantil, um projeto da Secretaria Estadual de Saúde do RS, desenvolvido pela Coordenação de Atenção Básica à Saúde Prisional junto ao Programa Primeira Infância Melhor (PIM). Tal projeto tem como objetivo articular ações de atenção à saúde às mulheres gestantes ou mães com filhos menores de 6 anos, privadas de liberdade e egressas do sistema prisional, bem como a suas familias, seus filhos e filhas, visando diminuir as iniquidades no acesso aos serviços do SUS e a fragmentação dos serviços, além de promover a integralidade da atenção à saúde dessa população.

\section{Resultados e Discussão}

À primeira vista, a penitenciária chama atenção não somente pelos graffitis nos seus muros, mas por sua arquitetura. Acontece que, na década de 1950, ali funcionava uma instituição de readaptação para mulheres consideradas desajustadas, a qual era mantida por uma congregação católica. Somente na década de 1970, a instituição passa a ser um órgão estatal, administrado pela Superintendência de Serviços Penitenciários (SUSEPE). Nesse período, tal como nos lembra Queiroz (2015), o espaço foi cenário de torturas de presas políticas durante a ditadura militar-civil-empresarial no Brasil. Isso revela o histórico caráter correcional e punitivista destinado às mulheres que, eram (e são) consideradas subversivas à moral burguesa e cristã hegemônica.

A ala da UMI, onde realizamos os encontros, é composta por dois andares: no segundo andar há quatro quartos compartilhados para as puérperas e seus filhos/as; no térreo, há um alojamento para as gestantes que é composto de uma única sala com cinco beliches distribuídas lado a lado. Ali também se encontram a lavanderia, os banheiros, o refeitório que se mistura à sala de convivência, a sala para atendimentos psicossociais, a coordenação da unidade e um pátio interno, além de uma sala sem porta destinada aos grupos (com TV, DVD, alguns brinquedos e uma pequena biblioteca). Interessante apontar para a ausência de porta nesta sala, pois a privacidade dos encontros ficava ameaçada pelos que se pode entender como parte dos mecanismos coercitivos e de exposição da intimidade típicos das instituições totais (GOFFMAN, 1996).

Nesse sentido, cabe trazer uma reflexão inicial sobre o papel da saúde frente 
aos dispositivos prisionais e sobre o processo de promoção da saúde nesse contexto, devendo ser levado em conta nas análises sobre as dificuldades e os paradoxos que as ações em tal cenário representam:

Se os grupos se propõem como um espaço de valorização das narrativas e das experiências das mulheres presas, podem esses, ao mesmo tempo, representar uma ameaça à ordem e ao tratamento prisional, ao passo que trabalham a partir de uma espécie ruptura com o cotidiano desse lugar? Ou então, podem eles representar um espaço de reafirmação da ordem a partir das relações de poder demarcadas na relação trabalhador-usuário, representada pela exposição do grupo? (DIÁRIO DE CAMPO, 2016).

A respeito da convivência grupal que se estabelece no presídio pode-se observar que, ainda que essa seja uma necessidade essencial do ser humano para manutenção de sua sobrevivência (MARX, 1983; PICHÓN-RIVIÉRE, 1998), nas instituições totais, esse contato é obrigatório. Através de mecanismos de padronização da vida, a PPL é compulsoriamente impelida a compartilhar celas, sanitários, horários das refeições e momentos de intimidade, perdendo a autonomia sobre si mesma e sua individualidade (GOFFMAN, 1996). Tendo isso em vista, o grupo se propunha como um ambiente aberto a acolher as demandas que fossem espontâneas às participantes. Pois, como alerta le Marcis (2016), a promoção da saúde no contexto prisional representa paradoxo no qual a privação de liberdade encontra-se em constante contradição com o princípio básico da promoção e educação em saúde: a autonomia do usuário.

Embora eu participasse dos grupos desde o ano de 2015, comecei a tomar notas no meu diário de campo apenas em janeiro de 2016, quando fui coordenador ${ }^{3}$ do grupo pela primeira vez, atuando como um orientador e facilitador da comunicação intragrupal, conforme preconizado por Pichón-Riviére (1998). Uma vez que os grupos ocorriam desde 2013 (ainda que com diferentes aportes teóricometodológicos), o vínculo grupal, considerado por Pichón-Riviére (2007) como um dos aspectos centrais desse processo, já se mostrava bastante estabelecido, mesmo tendo um formato aberto e de muita rotatividade das participantes em função das diversas questões que desenham os caminhos de saídas, entradas e trocas de galerias das mulheres nas prisões.

No primeiro encontro relatado, apresentamos a proposta de uma oficina de recorte e colagem cujo objetivo era produzir textos e imagens de forma livre, a fim de mobilizar dispositivos simbólicos na expressão dos conteúdos latentes do 
grupo, tais como desejos, sonhos e sentimentos que compunham aquele momento em suas vidas. Assim, discutimos questões como o sofrimento da maternidade encarcerada, os medos, o sonho da liberdade, as expectativas da saída do cárcere, o retorno à familia, ao trabalho e ao convivio com os filhos que permaneciam em liberdade. O mundo lá fora era visto como um lugar de possibilidades.

De acordo com Bakhtin (1992), essas expressões da linguagem, sejam por suas manifestações orais ou escritas, são enunciações da interação entre indivíduos socialmente organizados. Essa expressão pode ser feita, também, através do dispositivo da imagem, tal como a arte, como coloca Vygotsky (1999) quando aponta que a arte, enquanto um objeto cultural e, portanto, mediador entre o indivíduo e o social, possibilita diversas contribuições para o desenvolvimento humano. Dessa forma, a arte tem a capacidade de impactar os processos psíquicos ao passo que media e estabelece relações entre os sujeitos, sua realidade objetiva e o gênero humano (BARROCO \& SUPERTI, 2014).

Tal atividade auxiliou não somente na comunicação intragrupal, mas na exposição dos temas emergentes, os quais também colaboraram para o arranjo das futuras atividades no planejamento de setting terapêutico. $O$ setting, nesse contexto, caracteriza-se pela organização de procedimentos grupais como objetivos, delimitação de tempo de encontro, recursos materiais e referenciais teóricos utilizados pelos coordenadores para a intervenção (ZIMERMAN \& OSORIO, 1997). Apesar disso, deixamos claro que as propostas seriam flexiveis, a fim de manter a centralidade da tarefa nas necessidades do grupo (PICHÓN-RIVIÉRE, 1998).

$\mathrm{Na}$ semana seguinte, demos seguimento a exploração dos principais temas emergentes no encontro anterior, definindo que as próximas atividades seriam focadas em cinco grandes conteúdos: maternidade (o que é ser mãe e o vínculo materno-infantil), cidadania (Direitos Humanos e direito à saúde), práticas artísticas, autocuidado e esperança (desejos e percepções sobre a vida fora do cárcere).

Buscando dar conta das intervenções na dinâmica grupal, enquanto Equipe de Campo (EC) tomamos os aportes teórico-metodológicos do conceito de grupo operativo na compreensão das relações dialéticas, constantes e contraditórias que compõem os processos de aprendizagem e interação social nos grupos (PICHÓN-RIVIÉRE, 1998). Nesse sentido, procuramos compreender as múltiplas representações internas sobre a tarefa que $\circ$ grupo se propôs a realizar. Essa percepção é, segundo Pichón-Riviére (1998), um dos princípios organizadores que constituem a finalidade do grupo (nesse caso, a promoção da saúde), dizendo respeito ao modo pelo qual o grupo, e cada indivíduo que o integra, interage a partir do compartilhamento das suas necessidades próprias em torno dos objetivos. Cale dizer que nesse processo foram suscitadas formas de aprendizagens que, para o autor, são sinônimos de saúde mental, ao passo que 
se tratam de apropriações ativas da realidade, integrando experiências e estilos de aprendizagens, possibilitando novos olhares para distintos aspectos emergentes das relações interpessoais.

No encontro seguinte, apresentamos as cópias que havíamos feito das colagens produzidas na primeira oficina e propusemos unificá-las em um fanzine $e^{4}$. Tal proposta possibilitou que as produções tomassem uma composição ainda mais coletiva, além de que cada uma poderia levar para si a produção comum do grupo. Durante a atividade, discutimos sobre situações de negligência vivenciadas no presídio, tal como a falta de acompanhamento pré-natal enquanto fato que pode comprometer gravemente a saúde tanto da mãe como do bebê. Isso foi aventado pela inexistência, naquele momento, de um/a profissional ginecologista na Unidade Básica de Saúde prisional (UBSp). Também são recorrentes os relatos na literatura sobre a falta e a dificuldades na assistência pré-natal, ao parto e o puerpério, uma vez que essas são feitas, muitas vezes, de forma discriminatória - justificada pela noção as mulheres presas seriam "merecedoras" de sofrimento e punição (CARNEIRO \& VERÍSSIMO, 2016). Assim, mesmo tal acompanhamento sendo previsto pelo Plano Nacional de Saúde no Sistema Penitenciário - PNSSP (BRASIL, 2003), denuncia-se uma situação de grande violência e de privações não somente da liberdade, mas de um amplo conjunto de direitos fundamentais (DOTTA, 2014).

Na busca pela compreensão do papel histórico da mulher junto à criminalidade, a criminologia crítica evidencia múltiplas experiências de vitimização ao longo do ciclo vital e durante o cárcere. São citadas situações de negligência, abandono, violência intrafamiliar e institucional; abusos físicos, psicológicos e uso abusivo de drogas; situações de rua; dificuldade de acesso às redes de apoio social e comunitárias, bem como às políticas públicas de saúde, assistência social, educação e moradia (DOTTA; STOCK \& FUZINATTO, 2017). Tais situações configuram não somente um quadro de vulnerabilidade social, mas compõe com a vinculação das mulheres aos delitos (CAFFARENA et al., 2012; BARCINSKI \& CÚNICO, 2016).

Essa perspectiva busca entender de que forma os fatores sociais, culturais e econômicos montam a relação mulher-criminalidade, como, por exemplo, vínculos afetivas com parceiros que estão envolvidos na rede de tráfico, marginalização sócio-econômica e necessidade de provisão material à família. $A$ isso, as pesquisas apontam que as atividades informais de trabalho eram a principal fonte de renda familiar de pessoas presas (CAFFARENA et al., 2012; BRASIL, 2014a). Os dados de pesquisa indicam que $68 \%$ das mulheres presas têm relação com o pequeno

Trata-se de um material em formato de revista utilizado para o compartilhamento de ideias, críticas, reflexões e informações em mídias não-tradicionais a partir da escrita e de outras expressões artísticas. Tem como objetivo dar voz ao debate público acerca de temas muitas vezes silenciados. Frequentemente usado pelo movimento punk nas décadas de 1960 e 1970, tal técnica tem tomado diversos espaços de aprendizagem, tais como grupos e escolas etc. Por não exigirem uma linguagem formal, são livres manifestações de seus produtores (MAGALHÃES, 1993).
} 
tráfico de drogas, o que pode ser identificado a partir do papel que essas ocupam nesse contexto. Ou seja, transportando drogas de um lugar para o outro, não ocupando, em geral, um papel de gerência sobre o tráfico e estando, assim, mais suscetiveis à captura policial (BARCINSKI; CÚNICO, 2016; BRASIL, 2014a).

Apesar disso, é importante apontar que esta posição no mundo do tráfico não deve ser vista como uma regra, pois algumas mulheres também ocupam papéis de gerência do tráfico, em geral, junto aos seus companheiros. Tal lugar, como afirmam Barcinski e Cúnico (2016), ainda que pouco habitado pelas mulheres, subjuga homens e mulheres ao seu poder, porém, não sem limitações decorrentes das diferenças de gênero. Daí a necessidade de olhar esse fenômeno desde uma perspectiva relacional, a fim de não remontar uma noção hegemônica de que as mulheres estariam menos capacitadas, biológica e/ou psiquicamente, a cometer crimes do que homens, uma vez que, desde tal ponto de vista, pode-se tomar a mulher como um não-sujeito, ou seja, um ser incapaz de possuir funções que são atribuídos historicamente à masculinidade (BARCINSKI; CÚNICO, 2016). Apesar disso, tomando em vista a colocação das autoras, tal reflexão não pode ser descolada do contexto no qual esse fenômeno ocorre, uma vez que as configurações expressas no mundo do tráfico refletem as opressões e as limitações de uma sociedade estruturalmente capitalista e patriarcal, sendo que as gerências femininas do tráfico ainda denunciam desigualdades e opressões.

No encontro seguinte, conforme combinado anteriormente, levamos cópias do Marco Legal pela Primeira Infância (BRASIL, 2016) para cada uma das mulheres. Divulgado no mês anterior ao encontro, o documento alterou o Estatuto da Criança e do Adolescente (ECA), o Código de Processo Penal e a Consolidação das Leis do Trabalho (CLT), trazendo mudanças significativas às mulheres privadas de liberdade que estão gestantes, são mães e/ou responsáveis legais de crianças até 12 anos de idade. A partir dessa lei, as mulheres nessas condições podem aguardar o julgamento em prisão domiciliar, desde que sejam presas provisórias (visto que teriam cometido crimes de menor teor ofensivo como o porte de drogas, pequenos furtos e danos ao patrimônio). Essa medida visa possibilitar que muitas dessas mulheres possam acompanhar o desenvolvimento de seus filhos/as fora do cárcere durante o processo de julgamento. Tal disposição é de grande importância, uma vez que pelo menos $65 \%$ das mulheres presas nas capitais e regiões metropolitanas estão gestantes e ou têm filhos (LEAL et al., 2016) e, além disso, o número de presas provisórias chega a $30 \%$ no Brasil e a $34 \%$ no RS (BRASIL, 2014a).

Apesar disso, é sabido que o atual sistema de justiça é lento e burocrático, dificultando a operacionalização das disposições previstas por esse documento. grupo expôs em diversos momentos esse acúmulo vivencial sobre os trâmites jurídico-penais. Ainda que a EC levasse algumas novidades sobre novas leis e portarias, principalmente no que se refere ao acesso à saúde, as 
mulheres contribuíram com seus conhecimentos acerca das questões penais, fato que tornava nossas discussões amplas e caracterizava uma aprendizagem compartilhada e horizontal.

No encontro posterior, assistimos ao filme "O Quarto de Jack" (O QUARTO, 2015). O drama narra a história de uma criança de quase cinco anos de idade que, desde o seu nascimento, fora mantida em cativeiro em um pequeno quarto junto à mãe. A criança era privada de qualquer contato com o mundo externo a se não através de um aparelho televisor, uma claraboia e o sequestrador de sua mãe. A exibição do filme, a liberdade de escolher o que era trazido e debatido no grupo, bem como a possibilidade de levarmos pipoca e suco de uva (algo pouco comum naquele espaço), mostraram-se como atos de valorização da singularidade do grupo bem como de resistência às rígidas regras de padronização da vida da instituição por parte do grupo.

No debate, a narrativa do filme foi relacionada às diversas significações atribuída por parte das mulheres às suas vivências durante a privação de liberdade, tais como o isolamento e o sofrimento da mãe não só por estar presa, mas por ver seus filhos também presos e limitados em relação ao contato com o mundo. Um dos fatos que exemplifica essa identificação é que algumas das crianças, com menos de um ano de idade e que viviam na UMI, tinham o contato com a familia bastante limitado por conta da privação de liberdade da mãe.

Foram em circunstâncias como essas que expôs-se uma contradição fundamental sobre o exercício da maternidade nesse contexto. Se por um lado, o período inicial da vida do bebê, a amamentação e o cuidado da mãe são de extrema importância tanto para o desenvolvimento de seus filhos quanto para o bem-estar materno, por outro, o cárcere representa um ambiente estressor, inadequado e adverso ao crescimento saudável dos bebês. Essa contradição entre o cuidado essencial nos primeiros anos de vida e o ambiente adverso das prisões é apontada, na literatura, como situação bastante recorrente às mulheres presas (CARNEIRO; VERÍSSIMO, 2016).

Ainda que seja assegurado à mãe permanecer com a criança durante o período de amamentação por, no mínimo seis meses (BRASIL, 1984) e até um ano de idade, no caso do RS, são frequentes as queixas das presas frente à impossibilidade do exercício de suas funções maternas de forma satisfatória. Isso por que as mães têm que dar o cuidado aos filhos/as em meio a críticas situações sanitárias e ambientais, espaços restritos e violentos e sem estímulos ao desenvolvimento. De acordo com Carneiro e Veríssimo (2016), por conta da precariedade das condições de vida essenciais ao ser humano, principalmente nesse período, tais fatores são comprometedores do desenvolvimento infantil. Além disso, na maioria dos casos relatados, ocorreram cortes abruptos da relação entre as mães e seus filhos, já que esses, após saírem da UMI, em geral passam a residir com a família extensa. No caso de não possuírem familiares responsáveis 
ou outras questões impeditivas, as crianças são encaminhadas a instituições de acolhimento infantil para o processo de adoção.

Em relação à ruptura do vínculo materno-infantil Bowlby (1980) conclui que, uma vez separados, mãe e filho vivem uma experiência traumática, de angústia em relação ao objeto perdido. Assim, o sentimento de abandono é recíproco e, caso a separação seja prolongada, o enfraquecimento dos vínculos pode gerar consequências profundas à saúde e ao desenvolvimento integral da criança. Complementarmente, Winnicott (1990) aponta que o cuidado materno (ou de um cuidador primário) é de extrema importância para o desenvolvimento egóico da criança, uma vez que o bebê não existe sozinho, mas em um par.

A solidão do cárcere devido ao afastamento da família, principalmente por conta das dificuldades financeiras e a distâncias dos presídios dos locais de origem das mulheres, torna esse contato ainda mais escasso. Ademais, as crianças mantidas com as mães presas têm suas relações com o restante da família fragilizada, caracterizando um ameaça aos seus vínculos interpessoais (CARNEIRO; VERÍSSIMO, 2016). Em relação às mulheres, esse distanciamento dos companheiros e da família também é vivida de forma traumática, sendo muitas vezes considerada uma consequência do estigma que recai sobre a criminalidade feminina por conta de representar uma ruptura aos ideais burgueses, hegemônicos nas sociedades ocidentais, de gênero e de família, que coloca as mulheres como sujeitos puros e vinculados ao cuidado do lar (BRAUSTEIN, 2007).

Tendo em vista tais questões, podem-se apontar que a experiência da maternidade no cárcere se apresenta num amplo aspecto de sofrimento e adoecimento físico e psíquico. Tal como Schneider e Ramires (2007) apontam, fatores como a falta de estímulos e a institucionalização influenciam diretamente, de forma nociva, na construção de bases saudáveis para o desenvolvimento de habilidades sociais e de aprendizagens ao longo do ciclo vital, uma vez que é na primeira infância que o sujeito começa a dominar niveis psicomotores, cognitivos, sociais e afetivos cada vez mais complexos. A reprodução de violências institucionais, atendimentos inadequados às gestantes, às puérperas e às crianças, bem como as dificuldades de acesso às políticas públicas em geral, negligências, traumas interpessoais, exposição a substâncias tóxicas durante a gestação, depressão materna, ambiente inadequado e, enfim, a vulnerabilidade social e familiar representam efeitos prejudiciais ao desenvolvimento infantil, das mães e da sociedade como um todo (SCHNEIDER \& RAMIRES, 2007; CARNEIRO \& VERÍSSIMO, 2016; LEAL et al., 2016).

Diante desse cenário de grande vulnerabilidade social, emocional e econômica das mulheres presas e das condições inadequadas de saúde neste contexto, algumas questões fundamentais emergiram e demarcaram o trabalho em seu processo: quais os objetivos e os meios para a promoção da saúde no ambiente prisional? Como nos utilizamos dos apoios teórico-metodológicos de forma a 
avançar diante desses paradoxos? Ou, se eles ainda são limitados, como superálos? Como é possivel potencializar o processo grupal e as articulações das redes da atenção à saúde a fim de qualificar o olhar dirigido à maternidade encarcerada e ao aprisionamento feminino? Como lidar com as contradições entre desenvolver uma escuta sensivel (e uma intervenção terapêutica) e manter um olhar crítico acerca das possiveis legitimações dos mecanismos do sistema penitenciário?

Frente a isso, buscamos, enquanto grupo, reconhecer as demandas, os objetivos e as razões de existir daquele grupo que se constituiu, num processo coletivo que, de acordo com Yalom e Leszcz (2006), tende a fortalecer os sentimentos de pertença dos participantes. Assim, retomamos a proposta da Linha de Cuidado Intersetorial enquanto uma ação de significativo avanço no acesso da PPL às políticas de saúde no Brasil e a necessidade de um olhar de equidade e integralidade a essa população pois, ainda que tais direitos estejam previstos pela Lei de Execuções Penais - LEP (BRASIL, 1984) as diversas denúncias apontam que suas ações mostram-se limitados a um modelo assistencial e curativo, esvaziando-se, portanto, de uma perspectiva e saúde pública (BRASIL, 2008). É somente com a Constituição Federal de 1988 e a consolidação do Sistema Único de Saúde - SUS (BRASIL, 1990) que outro cenário fez-se possivel às disposições para a promoção, proteção, recuperação e acesso à saúde.

Entretanto, os avanços significativos em relação à saúde da PPL somente começaram a ocorrer através do PNSSP (BRASIL, 2003) e com o surgimento, anos mais tarde, da Política Nacional de Atenção Integral à Saúde no Sistema Prisional - PNAISP (BRASIL, 2014c), expressando um grande avanço no acesso à atenção básica à saúde da $\mathrm{PPL}{ }^{5}$. Esta política retoma as diretrizes da Política Nacional de Atenção Básica - PNAB (BRASIL, 2011) e define as ações de promoção e prevenção da saúde na rede do SUS nos municípios, articulando seus dispositivos a fim de minimizar os agravos provocados pelas condições do cárcere. No ano de 2014, também é estabelecida a Política Nacional de Atenção às Mulheres em Situação de Privação de Liberdade e Egressas do Sistema Prisional - PNAMP (BRASIL, 2014d). Contudo, a realidade do sistema prisional continua sendo uma questão a ser aprofundada, uma vez que as dificuldades históricas representadas pelo terreno de disputas políticas, econômicas e ideológicas no qual o SUS se encontra torna esse campo ainda bastante complicado.

A nivel das interações grupais resgatamos questões como o sigilo grupal e a diferenciação da atuação da saúde coletiva e da segurança, a fim de esclarecer diferenças cruciais: a compreensão, por parte da saúde, das mulheres enquanto sujeitos de direitos, de autonomia e não de estigma e sofrimento. Essa diferenciação paralisava o espaço institucional pois, tanto as presas quanto a instituição têm

5 O trabalho realizado pela SES/RS é reconhecido como uma das maiores influências para a consolidação de tal política, sendo o primeiro Estado a avançar significativamente nos financiamentos para as habilitações das Equipes de Atenção Básica prisionais (EABP). Hoje temos uma cobertura de acesso à atenção básica aproximadamente 70\%, da PPL (SES, 2017). 
dificuldade em reconhecer as primeiras enquanto "merecedoras" deste espaço de promoção da saúde, por conta da lógica punitivista ser majoritariamente vigente no cárcere. Logo, o rompimento da cadeia de violência interpessoal e das rotas de revitimização é um importante elo de ligação com a EC, bem como de libertação das amarras subjetivas a experiências traumáticas.

O encontro seguinte foi acompanhado pelo médico pediatra da UBSp que auxiliou na condução de uma oficina de educação em saúde, servindo de apoio às dúvidas sobre saúde sexual e reprodutiva, gestação, pré-natal, puerpério e implicações desses processos nas mudanças corporais e hormonais, além de questões sobre o desenvolvimento infantil. Assim, em consonância com as estratégias previstas pela PNAISP (BRASIL, 2014c), buscou-se, desde uma perspectiva de integralidade sobre os processos de saúde-doença-atenção, atuar para além de ações preventivas, mas de promoção da qualidade de vida. Assim, tendo, em conta os esforços técnicos e políticos direcionados não somente à mudança de comportamentos e estilos de vida, mas a modificações estruturais, a fim de colaborar com o enfrentamento das desigualdades e iniquidades sócio sanitárias no âmbito do SUS de forma ampla (BUSS, 2000; CZERESNIA \& FREITAS, 2009).

É ainda dentro dessa perspectiva que a promoção da saúde busca valorizar o fortalecimento da autonomia, além de mecanismos básicos de aprendizagens e mudança, articulando saberes técnicos-científicos e populares junto a estratégias institucionais e comunitárias de diferentes setores públicos, sendo complementar às demais intervenções da saúde pública (CZERESNIA \& FREITAS, 2009). A respeito disso, tomando em conta a diversidade de saberes que compunha o grupo, pode-se dizer que as gestantes, as lactantes, os/as residentes, os/as estagiários/ as e os/as trabalhadores/as da saúde, teceram, juntos, uma rede de aprendizagens compartilhadas que demarca uma continuidade ou um eco dessa experiência que se estende para muito além do trabalho realizado naquele período temporal.

Em função da interdição da UMI, por conta de uma viga que estava caindo próxima à porta de acesso, as mulheres que lá estavam foram transferidas para outra penitenciária do Estado. Assim, a EC deslocou-se até esse outro campo para realizar o grupo junto à psicóloga da UBSp. Embora a penitenciária fosse mais isolada em relação à cidade do que a anterior, a infraestrutura física era bastante conservada e limpa, aparentando, a princípio, um aspecto mais adequado (se é que isso é possivel) para receber as presas. Apesar disso, as paredes cinzas (que contrastam com os graffitis da instituição anterior), a proximidade da UMI às celas de isolamento (de onde se ouviam os gritos das mulheres no "castigo" 6 ), o ambiente abafado, o pequeno pátio coberto por grades e uma tela de arame, o grande número de insetos como aranhas e mosquitos, tornavam o ambiente totalmente insalubre. Ainda, outras dificuldades enfrentadas naquele momento, como a proximidade com $\circ$ Natal e Ano Novo, possivelmente facilitaram o reforço de sentimentos melancólicos 
e de abandono em função da impossibilidade das mulheres passarem esse tempo com seus familiares e seus outros filhos, me liberdade.

Além disso, os mecanismos de padronização através da exigência do uso de uniformes somados aos dispositivos de vigia tais como salas com vidros espelhados (dos quais se pode ver qualquer movimento das mulheres do outro lado sem que o observador possa ser visto), inclusive na sala destinada aos grupos, ameaçavam a privacidade dos encontros bem como o estabelecimento de um setting considerado seguro às mulheres, pois essas eram observadas em tempo integral. Não obstante, de acordo com as mulheres, as punições eram ainda mais constantes e severas, o que tornavam a experiência ainda mais traumática e hostil. Neste dia, o grupo mostrou-se bastante emotivo e mobilizado, expondo uma necessidade de escuta e acolhimento ainda maior por conta desse cenário.

A escuta empática para com as participantes é uma das posturas fundamentais aos coordenadores de grupos (ZIMERMAN \& OSORIO, 1997) para que seja possivel lidar com os sofrimentos causados por essas condições e pela falta de atendimento psicossocial adequados. Pode-se dizer, portanto, que o processo grupal apresentou-se como um dispositivo fundamental na promoção do vínculo e de um espaço seguro e terapêutico, mesmo com suas limitações. De acordo com Pichón-Rivière (1998), as articulações em torno da tarefa do grupo e dos processos de aprendizagem que este representa, cumprem uma função essencialmente terapêutica na promoção da saúde. Em consonância com isso, Yalom e Leszcz (2006) ressaltam que possibilidade da experiência catártica, instilação de esperança, compartilhamento de informações, aprendizagens interpessoais, fortalecimento das defesas do ego, da autoconsciência, das capacidades de insight e do reconhecimento de seus próprias valores e emoções mostram-se como aspectos terapêuticos substanciais ao grupo.

As férias de final de ano e a greve dos/as trabalhadores/as da SUSEPE7 acarretaram em uma interrupção abrupta dos encontros. Esta situação impossibilitou um fechamento adequado de nosso trabalho, sendo uma das grandes limitações impostas ao processo. Sabe-se que a fase conclusiva de um grupo se trata de um momento de avaliação de ganhos e dificuldades emergentes no processo grupal, portanto, deve ocorrer quando não há mais perspectivas de avanços significativos. A fase de conclusão de um espaço psicoterapêutico é bastante complexa e requer um preparo para que se possa dar conta dos processos de revisão, de luto e do início de uma nova fase. Dessa forma, um término arbitrário pode tornar a experiência de desligamento ainda mais difícil as participantes, bem como levantar fortes sentimentos de abandono (YALOM \&

tal política, sendo o primeiro Estado a avançar significativamente nos financiamentos para as habilitações das Equipes de Atenção Básica prisionais (EABP). Hoje temos uma cobertura de acesso à atenção básica aproximadamente 70\%, da PPL (SES, 2017).

$7 \quad$ A categoria decretou greve em função do pacote de medidas proposto pelo governo do Estado que precariza ainda mais as condições de trabalho (Correio do Povo, 2016). 
LESZCZ, 2006), embora não seja possivel avaliar tal situação. Nessa perspectiva, cabe não somente a autocrítica, mas o reconhecimento dos limites que se desenharam nesse campo, já que o período de luto deve ter a devida atenção, uma vez que esse rompimento pode comprometer não somente a experiência grupal, no que diz respeito a limitar o crescimento futuro do grupo e representar significativos retrocessos, ansiedade e depressão, mas da revitimização dessas mulheres cuja história é marcada por rompimentos e abandonos.

\section{Conclusão}

Os graffitis desenhavam, ao longo dos muros, histórias de mulheres, mães, negras, pobres, trabalhadoras [...], cujos olhos cheios de sonhos miravam o futuro. Não há a possibilidade de qualquer sujeito que consiga compreender as dimensões éticas do trabalho em saúde não se mobilizar diante da barbárie produzida no sistema de exploração capitalista e escancarada nos mecanismos ideológico, políticos e penais dos presídios. Reconhecer a dura e injusta realidade imposta à sua classe é passo fundamental para implicar-se eticamente nos processos de mudanças radicais a esse sistema (Diário de campo, 2017).

O encarceramento feminino vem exigindo um profundo debate em interface aos aspectos que compõem a totalidade das relações sociais, tais como as relações de gênero, raça, classe social, geração, violência, criminalidade e dos processos de saúde-doença-atenção, principalmente por conta das consequências que esse cenário tem representado às mulheres privadas de liberdade, seus filhos, sua família e à todos nós. Diante desse complexo contexto, duas questões essenciais podem ser levantadas nas análises trazidas a partir dessa experiência:

Em primeiro lugar, desde uma perspectiva macrossocial, expõem-se os desafios estruturais das políticas públicas em prover o acesso a direitos humanos fundamentais à PPL, mesmo que a garantia desses seja prevista pela Constituição Federal vigente e pelas leis que regem o SUS. Esse desafio encontra-se intrinsecamente ligado às políticas de criminalização das drogas e ao caráter punitivo das prisões, cujos mecanismos ideológicos erguem-se sobre a concepção de que, privar essa população de liberdade é também privá-las de direitos, e que tanto um quanto outro representam o que chamam de "justiça", a justiça burguesa. Além disso, a saúde encontra limitações tanto no sucateamento e na ameaça neoliberal que paira sobre o SUS como na ampla desigualdade social e pauperização das massas nos países da América do Latina.

Nesse sentido, a situação atual do sistema prisional, como tem cabido à mídia hegemônica chamar de "crise do sistema carcerário", nada mais é que a expressão de um projeto político, social e ideológico da classe dominante com vista à punição 
dos sujeitos marginais e desviantes das leis injustas estabelecidas pela primeira. Projeto esse que prova-se cada vez mais falido, ao passo que tal situação tende apenas a denunciar a impossibilidade do capitalismo de superar-se a si mesmo em seus processos de crises cíclicas e periódicas, a iminência das guerras, da fome, da pobreza, das doenças e de todas as situações de pauperismo social representadas pela sua essência, uma vez que tais aspectos são inerentes a sua estrutura.

Em segundo lugar, considerado de um ponto de vista microssocial, os grupos enquanto dispositivo de promoção da saúde representaram uma grande potência no que diz respeito a uma escuta empática e focada nas necessidades dessa população, além de serem um dispositivo terapêutico, de valorização da autonomia, de mobilização de aprendizagens interpessoais e, consequentemente, de fortalecimento do vínculo materno-infantil - mesmo com as contradições que esses aspectos representam diante do sistema prisional. Para além disso, essa experiência ainda abre precedentes para as possibilidades das articulações de distintos saberes e dos dispositivos institucionais a fim de garantir a atenção à saúde de forma integral a essa população, de forma a diminuir as iniquidades da atenção em saúde. Coloca-se "diminuir", pois ainda há muito o que avançar e porque, principalmente, não se pode humanizar um sistema que, em sua essência, desumaniza as relações a tal ponto que reproduz a barbárie que é a sociedade de classes.

A promoção da saúde no sistema prisional, nesse sentido, localiza-se num amplo campo de contradições que dizem respeito às potencialidades que emergem de um trabalho comprometido eticamente com os usuários e usuárias do SUS e das limitações que representam as políticas públicas e produção da vida no capitalismo. Em nível de experiência, um dos maiores desafios encontrase em manter as atividades de forma integrada, visando (além das demandas emergentes aos grupos como a saúde, a saúde mental, os direitos humanos e as disposições legais) proporcionar o fortalecimento do vínculo materno-infantil na perspectiva de colaborar para o desenvolvimento da primeira infância. Observase que essa última trata-se, sobretudo, da possibilidade da mãe ou da gestante em acessar a saúde de forma integral, uma vez que isso refletirá diretamente nas condições sociais, afetivas e ambientais propiciadas a seus filhos e filhas.

Finalmente, propõe-se que algumas outras questões sejam trazidas para os atuais e futuros debates acerca da promoção da saúde como a necessidade de formação profissional (técnica, teórica e metodológica) e do compromisso ética dos/as psicólogo/as como fatores essenciais na luta pela defesa da vida e do desenvolvimento humano. Espera-se que essa experiência inspire críticas, reflexões e oxigenação ao nosso modo de pensar e praticar a atenção à saúde no âmbito do SUS. Por tanto, deve-se encarar esse compromisso ético mantendo no horizonte de suas práticas a luta pelos direitos historicamente conquistados pelos trabalhadores, sem perder de vista a necessidade de superação do capitalismo rumo a uma nova forma de produção da vida, visto as consequências que esse tem 
representado sobre a vida de sujeitos pertencentes a uma classe historicamente violentada, oprimida, explorada e privada de direitos.

\section{Referências}

BARCINSKI, Mariana; CÚNICO, Sabrina Daiana. Mulheres no tráfico de drogas: retratos da vitimização e do protagonismo feminino. Civitas, Porto Alegre, v. 16, n. 1, p. 59-70, jan./mar. 2016. Disponivel em: <http://revistaseletronicas. pucrs.br/ojs/index.php/civitas/article/view/22590/14414>. Acesso em: 3 mai. 2017.

BAKHTIN, M. Marxismo e Filosofia da Linguagem. 6. ed. São Paulo: Hucitec, 1992.

BARROCO, Sonia Mari Shima; SUPERTI, Tatiane. Vigotsky e o estudo da Psicologia da Arte: Contribuições para o Desenvolvimento Humano. Psicologia \& Sociedade, Maringá, v. 26, n. 1, p. 22-31, 2014.

BRASIL. Lei n ${ }^{0} 7.210$ de 11 de julho de 1984. Lei de Execução Penal. Presidência da República, Casa Civil, Subchefia para Assuntos Jurídicos. Brasília, 1984.

- Centro de Documentação do Ministério da Saúde. $8^{\mathbf{a}}$ Conferência Nacional de Saúde. Brasillia, 1986.

Presidência da República. Casa Civil, Subchefia para Assuntos Jurídicos Constituição da República Federativa do Brasil de 1988.. Brasilia, 1988.

Secretaria-Geral da Presidência da República e Secretaria Nacional de Juventude. Mapa do encarceramento: os jovens do Brasil. Brasilia, 2015.

Ministério da Justiça. Departamento Penitenciário Nacional (DEPEN). Ministério da Justiça. Levantamento Nacional de Informações Penitenciárias (INFOPEN) Mulheres. Brasilia, 2014a. Disponivel em: <http://www.justica.gov. $\mathrm{br} / \mathrm{seus}$-direitos/politica-penal/relatorio-depen-versao-web.pdf $\rangle$. Acesso em: 28 out. 2016.

Departamento Penitenciário Nacional (DEPEN). Levantamento Nacional De Informações Penitenciárias. Brasilia, 2014b. Disponivel em: <http://www.justica.gov.br/seus-direitos/politica-penal/documentos/relatoriodepen-versao-web.pdf>. Acesso em: 8 abr. 2017.

Portaria Interministerial MS/ML n ${ }^{0} 01$ e 02 de janeiro de 2014. Política Nacional de Atenção Integral à Saúde das Pessoas Privadas de Liberdade no Sistema Prisional (PNAISP) no âmbito do Sistema Único de Saúde (SUS). 
Brasilia, 2014c.

Portaria Interministerial $n^{0} 210$ de 16 de janeiro de 2014. Política Nacional de Atenção às Mulheres em Situação de Privação de Liberdade e Egressas do Sistema Prisional. Brasilia, 2014d.

Lei $\mathbf{n}^{0} \mathbf{8 . 0 8 0}$, de 19 de setembro de 1990 . Dispõe sobre as condições para a promoção, proteção e recuperação da saúde, a organização e o funcionamento dos serviços correspondentes e dá outras providências. Gabinete do Ministério/ Ministério da Saúde. Brasilia, 1990.

Ministério da Saúde. Portaria Interministerial MS/MJ n 1.777 de 9 de setembro de 2003. Plano Nacional de Saúde no Sistema Penitenciário - PNSSP. Brasilia, 2003.

. Portaria $n^{0}$ 2.488, de 21 de outubro de 2011. Política Nacional de Atenção Básica (PNAB). Brasilia, 2011.

Ministério Público Federal. CPI do sistema carcerário: relatório final. Brasilia, 2008.

Marco Legal pela Primeira Infância. Lei Estadual n. 13.257, de 08 de Março de 2016. Brasilia, 2016.

BUSS, Paulo Marchiori. Promoção da Saúde e qualidade de vida. Ciência \& Saúde Coletiva, Brasilia, v. 5, n. 1, p. 163-177, 2000. Acesso em: <http://www. scielo.br/scielo.php?script=sci_arttext\&pid=S1413-81232000000100014\&lng =en\&nrm=iso>. Acesso em: 12 jun. 2017.

BOWLBY, J. Attachment and Loss (v. 3): Loss, Sadness and Depression. New York: Basic Books, 1980.

BRAUNSTEIN, H. R. Mulher encarcerada: trajetória entre a indignação e o sofrimento por atos de humilhação e violência. Dissertação (Mestrado em Educação) - Universidade de São Paulo, São Paulo, 2007.

CAFFARENA, B. M. et al. Mujeres en las cárceles de Andalucía. Madrid: Dykinson 2012.

CORREIO do povo. Servidores penitenciários do RS decidem paralisar em protesto contra pacote de Sartori. Correio do Povo, Porto Alegre, 19 dez. 2016. Disponivel em: <http://www.correiodopovo.com.br/Noticias/ Geral/2016/12/605834/Servidores-penitenciarios-do-RS-decidem-paralisarem-protesto-contra-pacote-de-Sartori . Acesso em: 6 jun. 2017.

CARNEIRO, Zaira Severino; VERÍSSIMO, Maria de La Ó Ramallo. Gestação e desenvolvimento infantil de bebês em situação de cárcere. Extensão em Ação, 
Fortaleza,v. 2, n11, p. 39-49, jul./out. 2016. Disponivel em: <http://www.revistaprex. ufc.br/index.php/EXTA/article/view/321/169>. Acesso em: 12 jun. 2017.

CZERESNIA, D.; FREITAS, C. M. (Orgs). Promoção da Saúde: conceitos, reflexões e tendências. 2. ed. Rio de Janeiro: Fiocruz, 2009.

DOTTA, R. M. The Right to Health: Woman in Prison and Mental Health. Dissertação (Doutorado em Ciências da Saúde e Epidemiologia das Doenças) Universidade de Ciências da Saúde de Porto Alegre, Porto Alegre, 2014.

DOTTA, Renata Maria.; STOCK, Bárbara Sordi; FUZINATTO, Aline Mattos. Privarlas de libertad es privarlas de salud? Interlocuciones entre género, salud pública y prisión a partir de la experiencia de un equipo de atención básica. Papers - Revista de Sociologia, España, v. 102, n. 2. p. 337-371, 2017. Disponível em: <http://papers.uab.cat/article/view/v102-n2-sordi-dotta-mattos/2341-pdf-es>. Acesso em: 12 jun. 2017.

GOFFMAN, E. Manicômios, prisões e conventos. Tradução Dante Moreira Leite. São Paulo: Perspectiva, 1996.

HOLLIDAY, O. J. Para sistematizar experiências. Brasilia, 2006.

LEAL, Maria do Carmo et al. Nascer na prisão: gestação e parto atrás das grades no Brasil. Ciência \& Saúde Coletiva, Rio de Janeiro, v. 21, n. 7, p. 20612070, jul. 2016. Disponivel em: <http://www.scielo.br/scielo.php?script=sci_ arttext\&pid=S1413-81232016000702061\&lng=en\&nrm=iso>. Acesso em: 11 jun. 2017.

LESSA, S.; TONET, I. Introdução à filosofia de Marx. 2. ed. São Paulo: Expressão Popular, 2011.

MARCIS, Frédéric Le. A impossivel governança da saúde em prisão? Reflexões a partir da MACA (Costa do Marfim). Ciência \& Saúde Coletiva, Rio de Janeiro, v. 21, n. 7, p. 2011-2020, jul. 2016. Disponivel em: < http://www.scielo.br/scielo. php?script=sci_arttext\&pid=\$1413-81232016000702011\&lng=en\&nrm=iso >. Acesso em: 5 jun. 2017.

MAGALHÃES, E. O Que é Fanzine. São Paulo: Brasiliense, 1993.

MARX, K. Contribuição à crítica da economia política. São Paulo: Martins Fontes, 1983.

MARX, K.; ENGELS, F. A Ideologia Alemã. Tradução Castro \& Costa, L. C. São Paulo: Martins Fontes, 2002.

ORGANIZAÇÃO DAS NAÇÕES UNIDAS (ONU). Resolução 2010/16 de 
22 de julho 2010. Regras das Nações Unidas para o tratamento de mulheres presas e medidas não privativas de liberdade para mulheres infratoras (Regras de Bangkok). ONU, 2010.

PICHÓN-RIVIĖRE, E. O Processo Grupal. 6. ed. Tradução Marco Aurélio Fernandes Velloso. São Paulo: Martins Fontes, 1998.

Teoria do Vínculo. 7. ed. Tradução Eliane Toscano Zamikhouwsky. São Paulo: Martins Fontes, 2007.

QUEIROZ, N. Presos que menstruam: A brutal vida das mulheres - tratadas como homens - nas prisões brasileiras. São Paulo: Record, 2015.

SCHNEIDER, A.; RAMIRES, V. R. Primeira Infância Melhor: uma inovação em política pública. Brasilia: UNESCO, Secretaria de Saúde do Estado do Rio Grande do Sul, 2007. Disponivel em: <http://issuu.com/primeirainfanciamelhor$\mathrm{pim} /$ docs/livropimumainovacaoempoliticapublic/5? $\mathrm{e}=13021856 / 10259307>$. Acesso em: 4 mai. 2016.

SECRETARIA ESTADUAL DA SAÚDE DO RIO GRANDE DO SUL - SES. Saúde Prisional. Disponivel em: <http://www.saude.rs.gov.br/saude-prisional>. Acesso em: 31 mai. 2017.

SOARES, Luiz Eduardo; GUINDANI, Miriam Krenzinger. A violência do Estado e da sociedade no Brasil contemporâneo. Nueva Sociedad, Buenos Aires, n. 208, p. 1-27, mar./abr. 2007.

VYGOTSKY, L. S. Psicologia da Arte. São Paulo: Martins Fontes, 1999.

WACQUANT, L. As prisões da Miséria. Rio de Janeiro: Jorge Zahar, 2001.

WINNICOTT, D. W. O ambiente e os processos de maturação. Porto Alegre: Artmed, 1990.

WORLD HEALTH ORGANIZATION EUROPE (WHO). Declaration on Prison Health as Part of Public Health. Moscou: 2003. Disponivel em: <http:// www.euro.who.int/__data/assets/pdf_file/0007/98971/E94242.pdf>. Acesso em: 28 mai. 2016.

YALOM, I. D.; LESZCZ, M. Psicoterapia de grupo: teoria e prática. 5. ed. Tradução Ronaldo Cataldo Costa. Porto Alegre: Artmed, 2006.

ZAFFARONI, Eugênio Raúl. Guerra às drogas e letalidade do sistema penal. Revista EMERJ, Rio de Janeiro, v. 16, n. 63 (Edição Especial), p. 115-125, out./ dez. 2013. 
ZIMERMAN, D. E.; OSORIO, L. C. (Orgs.). Como trabalhamos em grupos. Porto Alegre: Artmed, 1997.

\section{Filme}

O QUARTO de Jack. Direção: Lenny Abrahamson. Produção: David Gross e Ed Guiney. Roteiro: Emma Donoghue. Canadá/Estados Unidos/Reino Unido/ Irlanda: A24, 2015. 1 DVD (1h 58m), DVD, son, color.

Recebido em dezembro de 2017

Aprovado em maio de 2018 